\title{
STUDIES ON PAIN: QUANTITATIVE MEASUREMENTS OF TWO PAIN SENSATIONS OF THE SKIN, WITH REFERENCE TO THE NATURE OF THE "HYPERALGESIA OF PERIPHERAL NEURITIS"
}

\author{
By NOLTON BIGELOW, IRVING HARRISON, HELEN GOODELL, AND \\ HAROLD G. WOLFF \\ (From the New York Hospital, and the Departments of Medicine (Neurology) and Psychiatry, \\ Cormell University Medical College, New York City)
}

(Received for publication October 2, 1944)

The study of sensation in intact human skin has revealed that noxious stimulation results in the perception of pricking and burning pain (1, 2). Furthermore, patients with peripheral neuropathy often experience burning pain on contact with the bed clothes or with slight manual pressure, and yet report an impaired perception of pricking pain. There is disagreement as to whether these are entirely different qualities of pain, or rather aspects of the same quality, seemingly different because of time factors. An attempt has been made with quantitative methods to understand the significance of these two pain sensations of the skin.

\section{METHOD}

The technique which utilizes radiant heat as a source of painful stimulation (3) was used for measuring the threshold for both "pricking" and "burning" pain. Observations were made of the amount of thermal radiation just necessary to produce the sensation of pain. The light from a 1000 watt bulb was focussed on an area of blackened skin $3.5 \mathrm{~cm}^{2}$ in area. Intensity of stimulus was measured in gram cal. per sec. per $\mathrm{cm}^{2}$. An automatic shutter allowed the light to fall on the skin area for a measured period of time. At the end of a trial, the instructed subject reported the sensation. If no pain was experienced, the intensity was increased and the procedure repeated at 60 -second intervals, until the subject just perceived pain at the end of the exposure. The amount of energy necessary to produce pain was measured by a radiometer, and several measurements agreeing within \pm 5 per cent were taken to establish the threshold.

Each subject was carefully instructed as to the purpose and method of the investigation. For the "pricking" pain threshold there was clearly described the sensation of warmth mounting into heat which would suddenly, just at the end of a given exposure, "draw together" into a sharp prick or tingle. It was also demonstrated that the pain threshold or the "edge of pain" which the subject was asked to report would be similar to the sensation perceived on striking a pin point lightly against the skin. For the "burning" pain threshold, the sensation of warmth was described as mounting into heat which would turn not quite so suddenly, but nevertheless definitely, into a burning pain which could best be perceived at the end of a 5to 10-second exposure. This "burning" pain is localized readily in the area stimulated. There is no punctate discreteness, but rather a blunt or slightly diffuse character to the sensation. The location of the pain is perceived as less superficial than that of "pricking" pain and is sometimes described as deeply penetrating, especially by some patients with lesions of peripheral nerves. A characteristic feature of this "burning" pain is its longer duration as compared with "pricking" pain.

When the duration of stimulus was less than $3 \mathrm{sec}-$ onds, differentiation of the "burning" pain threshold from the "pricking" pain threshold was difficult. The trial exposures to the heat stimulus were well under the threshold, to demonstrate the sensation of heat without pain. This was especially important with anxious, apprehensive subjects. It was found that untrained but instructed subjects could most readily distinguish the endpoint for "burning" pain with a 5- to 10-second exposure, whereas a 3-second exposure had been found most suitable for discerning a sharp end-point for "pricking" pain.

When an explanation of the technique and the sensation to be experienced was not clearly given, the subjects were doubtful what the end-point might be and were overanxious to be cooperative and certain and therefore waited until they had experienced a "good, sharp jab of pain" before reporting an end-point. Thus, considerably more variation in the individual evaluation of the pain threshold existed without instruction as to what to observe and report, than with such instruction.

The instruction which was given to the subjects was in the same category as that given to a student to enable him to read an end-point in a titration, or in a colorimeter, or to read a Vernier Scale. In other words, it was the aim to instruct the subject as to what was the exact target he was expected to hit.

Once the instruction was presented and the observation begun, further instruction and suggestion were scrupulously avoided. The subject was not told by the operator during the tests that at this or that stage of the procedure he would experience pain, or that "now you will feel pain." In fact, no suggestion whatever was made during the period of the reading.

The method employed in these experiments for the 
quantitative measurement of pain threshold was similar to that which has been used in other investigations and the procedures have been reported elsewhere ( 3 to 10$)$.

I. COMPARISON OF PROPERTIES OF "BURNING" AND

\section{Observations}

$$
\text { "PRICKING" PAIN }
$$

Series 1. The threshold for "burning" pain was ascertained on the skin of the forehead of 23 subjects. In this limited series, the variations from subject to subject were \pm 16 per cent. The data for "burning" and "pricking" pain thresholds on the skin of the forehead of 11 subjects are averaged and represented in Figure 1. Invariably, on normally innervated skin, the threshold for "burning" pain was found to be lower than that for "pricking" pain.

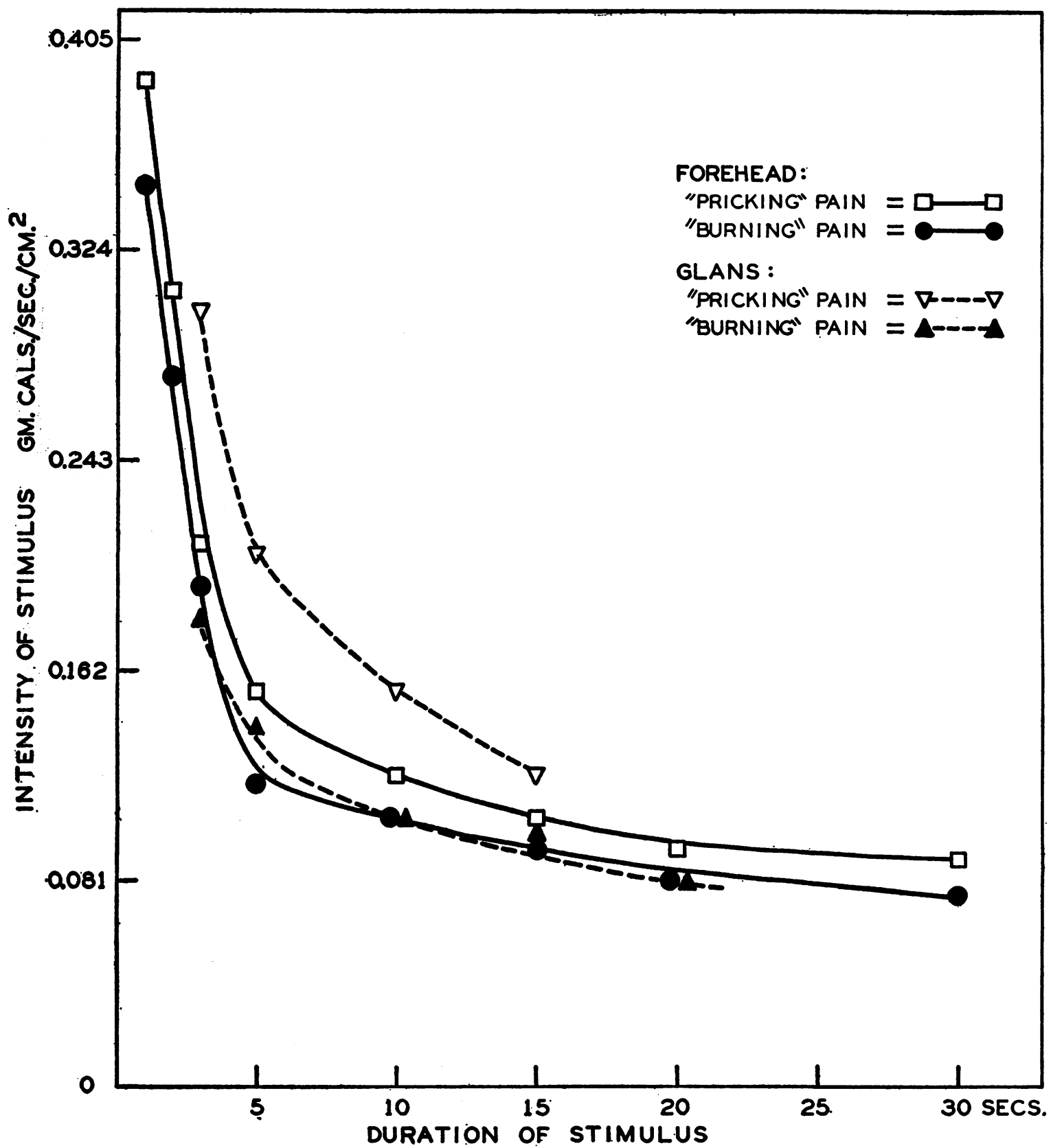

Fig. 1. Thresholds of "Pricking" and "Burning" Pain on the Glans and on the Skin of the forehead 
Series 2. The effects of analgesic agents upon the thresholds of "pricking" and "burning" pain were observed. Six observations were made on 3 subjects. It was found that ethyl alcohol (60 ml., 95 per cent) raised the threshold of both "burning" and "pricking" pain about the same percentage above their control levels. Acetylsalicylic acid also raised the threshold of both "burning" and "pricking" pain approximately the same percentage above control levels, although, to be sure, these 2 agents differed from each other in their effects $(6,9,10)$.

Series 3. To ascertain whether spatial summation occurs with "burning" pain, pain thresholds were measured on areas of skin $0.4 \mathrm{~cm} .^{2}$ to 11.6 $\mathrm{cm}^{2}$ in area, on 4 subjects in 5 trials. Thresholds for "burning" pain in these subjects varied no more than 25 per cent from the smallest to the largest areas of skin stimulated, which indicates that no spatial summation of significance occurs. It has already been demonstrated that significant spatial summation does not occur for "pricking" pain (3).

Series 4. Comparative observations of pain thresholds were made on the skin of the forehead and on the surface of the glans penis in 7 of the 11 normal subjects, and the data of the observations are represented in Figure 1. The "burning" pain threshold on the glans was found to be the same as on the skin of the forehead. As the intensity of the stimulation on the surface of the glans was increased on further trials, the "burning" sensation became more intense until either a "pricking" component was experienced, or the subject stated that he was unable to distinguish the sensations. With stimuli of high intensity and short duration, a distinction between the 2 end-points was extremely difficult and data about these 2 end-points under such circumstances are unreliable. From Figure 1, it is evident that the thresholds for "burning" pain both on the glans and on the skin of the forehead were approximately the same for stimuli of longer duration. The threshold for "pricking" pain on the glans appeared to be higher than on the skin of the forehead, but owing to the difficulty of perceiving "pricking" pain on the glans, these quantitative aspects of the data cannot be accepted too literally.

Series 5. Thresholds for "burning" and "pricking" pain were ascertained in 4 trials on 3 subjects who had "sunburns" or ultraviolet burn, of various degrees of severity. The threshold for "pricking" pain was reduced 43 to 52 per cent; that for "burning" pain 63 to 97 per cent from their respective control levels, ascertained on the same areas of skin on a day previous to the tissue damage (Table I).

TABLE I

Skin inflammation and pain thresholds

\begin{tabular}{|c|c|c|c|c|}
\hline \multirow{2}{*}{$\underset{\text { ject }}{\text { Sub- }}$} & \multirow{2}{*}{$\begin{array}{c}\text { Area of skin } \\
\text { injured }\end{array}$} & \multirow{2}{*}{$\underset{\text { injured }}{\text { How }}$} & \multicolumn{2}{|c|}{$\begin{array}{l}\text { Pain threshold } \\
\text { change }\end{array}$} \\
\hline & & & $\begin{array}{l}\text { "Prick- } \\
\text { ing" }\end{array}$ & "Burn- \\
\hline & & & \multicolumn{2}{|c|}{ per cent } \\
\hline $\begin{array}{l}\text { N. B. } \\
\text { N. B. }\end{array}$ & $\begin{array}{l}\text { Over deltoid muscle } \\
\text { Over forearm }\end{array}$ & $\begin{array}{l}\text { Sunlight } \\
\text { Ultraviolet }\end{array}$ & $\begin{array}{l}-43 \\
-52\end{array}$ & $\begin{array}{l}-63 \\
-97\end{array}$ \\
\hline $\begin{array}{l}\text { I. H. } \\
\text { O. B. }\end{array}$ & $\begin{array}{l}\text { Over deltoid muscle } \\
\text { Over deltoid muscle }\end{array}$ & $\begin{array}{l}\text { Sunlight } \\
\text { Sunlight }\end{array}$ & $\begin{array}{l}-51 \\
-47\end{array}$ & $\begin{array}{l}-86 \\
-92\end{array}$ \\
\hline
\end{tabular}

\section{Comment}

Schumacher (11) has also reported the reduction of the "pricking" pain threshold of inflamed skin. The greater reduction in the "burning" pain threshold in inflamed areas of skin explains why slight stimulation of a "sunburned" skin characteristically elicits a "burning" pain sensation.

Series 6. In a patient with radiculitis, the thresholds for "pricking" and "burning" pain over an area of "hyperalgesic" skin of the left arm, were compared with normally innervated skin areas on the arms and on the forehead. The threshold for "burning" pain was about 20 per cent lower on the abnormally innervated skin area, whereas the threshold for "pricking" pain was elevated about 20 per cent (Figure 2).

A patient had "hypoalgesia" to pin prick on parts of his left hand. Rubbing the skin induced a burning sensation. At surgical operation, a displaced intervertebral disc of the sixth cervical vertebra was found. In Table II are shown the threshold measurements for "burning" and "pricking" pain ascertained on control areas of the intact hand and on the forehead, compared with thresholds ascertained on the affected hand. The quantity of radiant energy required to attain the threshold of "burning" and "pricking" pain at various time exposures is expressed in gram cal. 


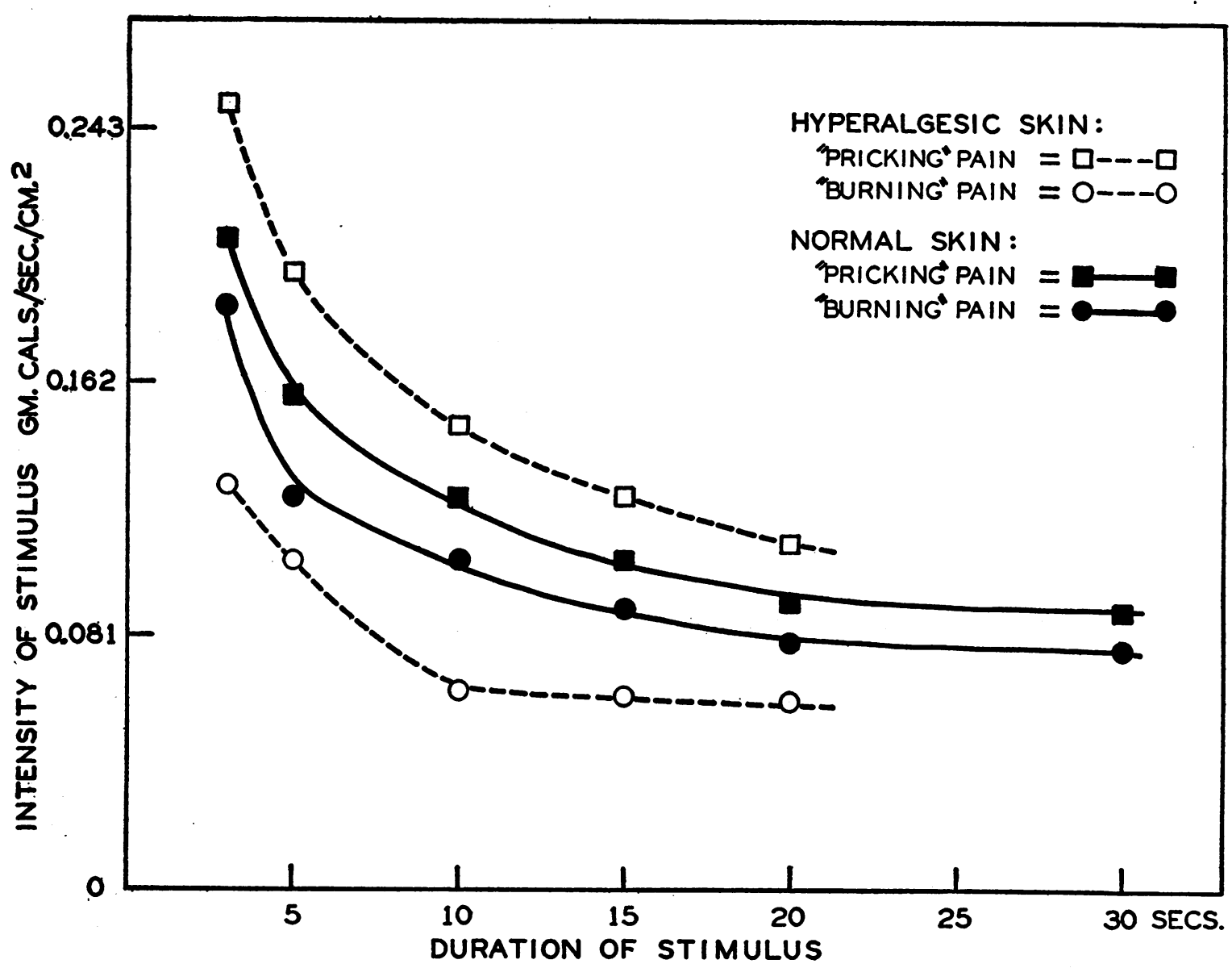

Fig. 2. Comparison of Thresholds of "Burning" Pain to "Pricking" Pain in a Patient with Hyperalgesia as a Result of Radiculitis

per sec. per $\mathrm{cm}^{2}$. From this table, it can be seen that the threshold for the "burning" pain of the abnormally innervated skin was less than on control areas, whereas the threshold for "pricking" pain was higher on the abnormal skin than on control areas.

TABLE II

Thresholds for "burning" and "pricking" pain on an area of "hypoalgesic" skin compared with thresholds on control areas

\begin{tabular}{|c|c|c|c|c|c|c|}
\hline \multirow{2}{*}{$\begin{array}{c}\text { Length } \\
\text { of } \\
\text { stim- } \\
\text { ulus }\end{array}$} & \multicolumn{3}{|c|}{$\begin{array}{c}\text { Thresholds for "burning" } \\
\text { pain }\end{array}$} & \multicolumn{3}{|c|}{$\begin{array}{l}\text { Thresholds for "pricking" } \\
\text { pain }\end{array}$} \\
\hline & $\begin{array}{c}\text { Con- } \\
\text { trol }\end{array}$ & $\begin{array}{l}\text { "Hypo-" } \\
\text { algesic" }\end{array}$ & $\begin{array}{c}\text { Devia- } \\
\text { tion }\end{array}$ & $\begin{array}{l}\text { Con- } \\
\text { trol }\end{array}$ & $\begin{array}{l}\text { "Hypo- } \\
\text { algesic" }\end{array}$ & $\begin{array}{c}\text { Devia- } \\
\text { tion }\end{array}$ \\
\hline seconds & \multicolumn{2}{|c|}{$\begin{array}{l}\text { gram cal. per sec. } \\
\text { per } \mathrm{cm}^{2}{ }^{2}\end{array}$} & per cent & \multicolumn{2}{|c|}{$\begin{array}{l}\text { gram cal. per sec. } \\
\text { per cm.2 }\end{array}$} & per cent \\
\hline $\begin{array}{r}5 \\
10 \\
15\end{array}$ & $\begin{array}{l}0.134 \\
0.112 \\
0.096\end{array}$ & $\begin{array}{l}0.089 \\
0.068 \\
0.064\end{array}$ & $\begin{array}{l}-33 \\
-40 \\
-34\end{array}$ & $\begin{array}{l}0.181 \\
0.152 \\
0.113\end{array}$ & $\begin{array}{l}0.219 \\
0.178 \\
0.142\end{array}$ & $\begin{array}{l}+21 \\
+17 \\
+26\end{array}$ \\
\hline
\end{tabular}

Series 7. Seventeen patients with "hyperalgesic" skin due to peripheral nerve disorder were observed. Three patients with herpes zoster and 14 patients with peripheral neuritis, from such varied causes as nutritional deficiency, dorsal root inflammation, and diabetes, exhibited a lowered threshold of "burning" pain, 15 to 35 per cent below control thresholds of normal skin areas on the same subject. Frequently, the "pricking" pain threshold in the affected areas was elevated.

Series 8. "Hyperalgesia" was experimentally produced in 6 subjects by occlusion of the circulation of the upper arm with a blood pressure cuff inflated to $200 \mathrm{~mm}$. $\mathrm{Hg}$ for 35 to 75 minutes. Care was taken that the arm was not moved and that pain did not occur spontaneously. If pain developed, the experiment was discontinued. It 
is known (3) that when the surface of the skin is cold, more radiant energy is required to elicit pain than when the skin surface is warm. Since the skin temperature of an ischemic arm falls gradually to room temperature, the latter was kept at 30 to $31^{\circ} \mathrm{C}$. during experiments. Measurements of pain thresholds were made on the dorsum of the wrist at intervals of 2 to 3 minutes. There was observed a slight fall in "pricking" pain threshold during the first 10 minutes, followed by a rise (see Figure 3 ). The threshold for "burning" pain, however, fell for about 20 minutes and began to rise after 25 minutes of ischemia. Thus, between 10 and 25 minutes, the "burning" pain threshold was depressed 28 to 32 per cent, while the "pricking" pain threshold was rapidly elevated. It was also noted that as the threshold of "burning" pain became depressed during the ischemia, the pain elicited by noxious stimulation of the skin persisted often for 5 seconds or longer, after the stimulus ended.

The persistence of pain after a noxious stimulus was most evident when the threshold of "burning" pain was most depressed. However, the "after pain" gradually diminished in duration as the threshold of "burning" pain became elevated during prolonged ischemia, and finally was not to be noted as the arm became almost insensitive.

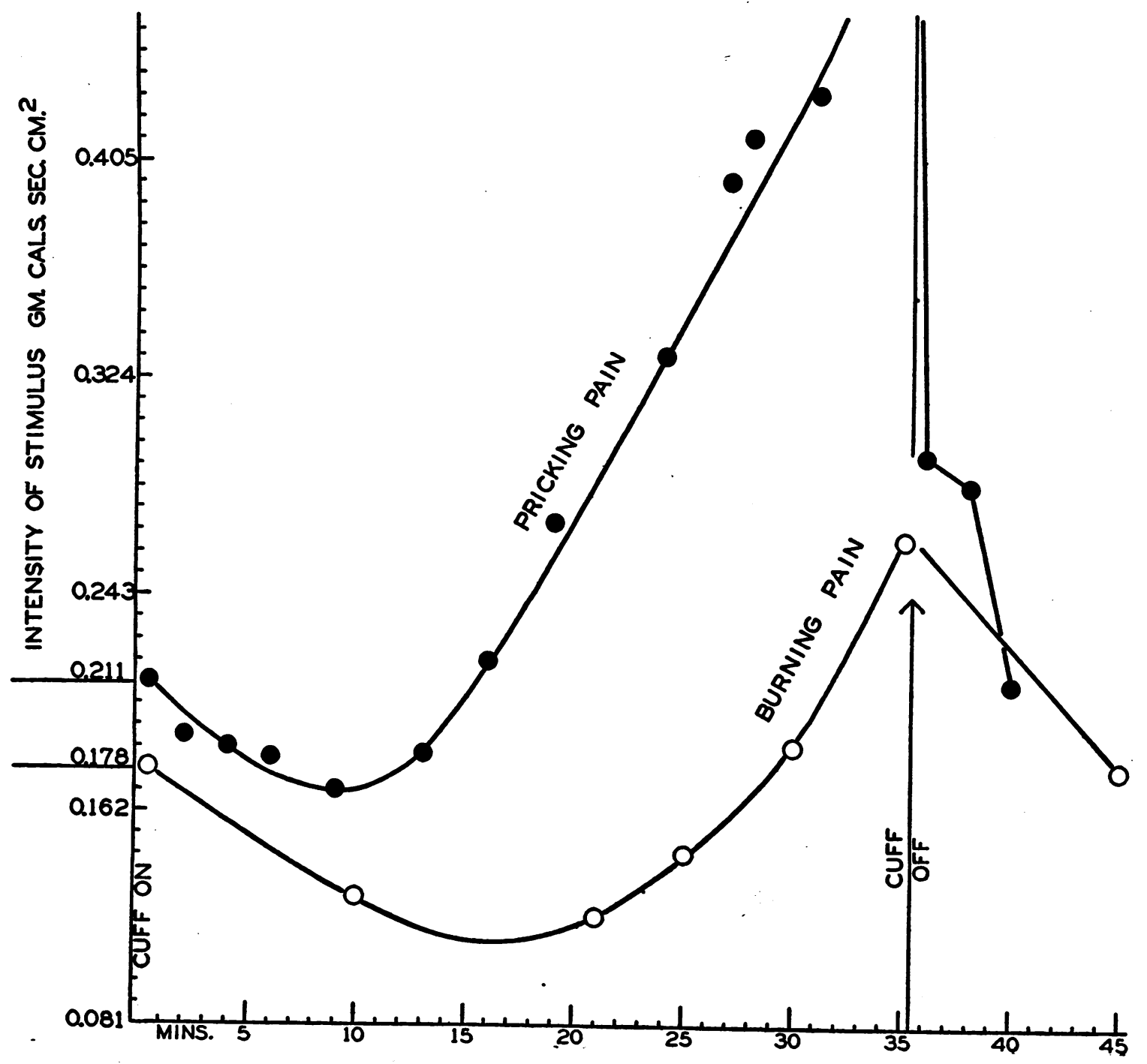

Fig. 3. Ischemia and the Pain Threshold 


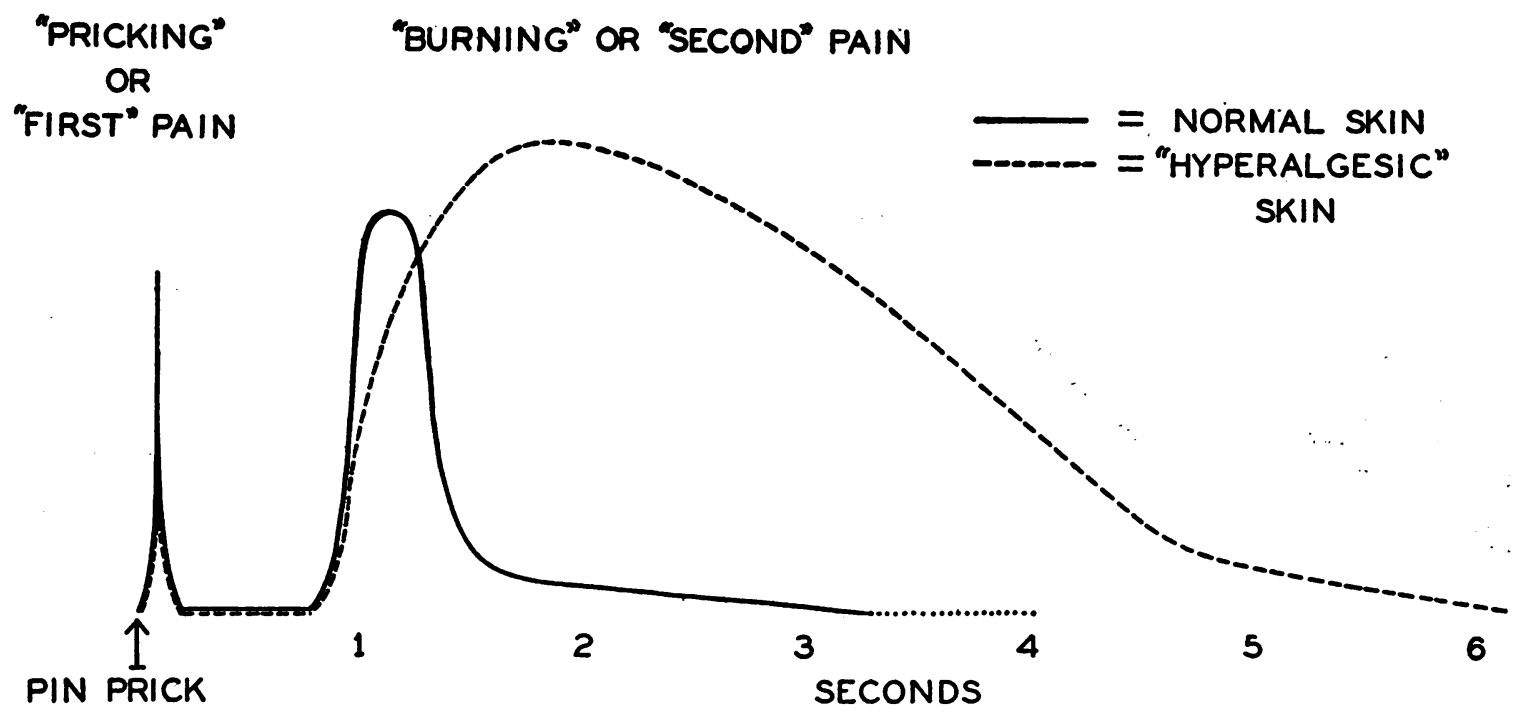

Fig. 4. Schematic Representation of Temporal Components of "Burning" and "Pricking" Skin Pain in Healthy Persons as Contrasted with Patients Having "Hyperalgesia" Associated with Peripheral NeuROPATHY

In one trial, when ischemia was maintained for 75 minutes, complete analgesia ensued.

\section{THE DOUBLE RESPONSE}

Many investigators have demonstrated that when pain is induced by pin prick or heat in the distal parts of an extremity, the sensation of "pricking" pain is followed after a painless interval by a second painful sensation. This has been called the "double response" $(1,2,12,13)$ (Figure 4). An attempt has been made in the following experiments to ascertain whether the quality of the first pain response, or rapidly perceived pain which will be designated as "fast" pain, was identical with that of the second response or the pain perceived later. The latter will be designated as "slow" pain.

\section{Method}

For purposes of pain stimulation, a sharp needle was thrust briefly and superficially into the skin surface; a brass cylinder heated to about $65^{\circ} \mathrm{C}$. was briefly touched against the skin; also, the Hardy, Wolff, Goodell pain threshold apparatus was used to stimulate pain by radiant heat. These noxious stimuli, both pin prick and thermal, were applied on the distal portions of the upper and lower extremities. In a second series of observations, experimental "hyperalgesia" in normal subjects was achieved by wrapping a blood pressure cuff around the upper arm and keeping it inflated to $200 \mathrm{~mm}$. $\mathrm{Hg}$ throughout the experiment (35 to 75 minutes). For "procaine block" a solu- tion of procaine hydrochloride, 1 per cent, was infiltrated either into the tissues around the ulnar nerve, or subcutaneously.

Series 1. Observations on the two qualities of pain of the double response

$a$. Nineteen subjects noted the double response and each subject was asked whether he considered the two sensations of similar quality. Eight subjects considered that they were the same; 2 would make no decision and 9 were convinced of a difference.

b. A patient with "hyperalgesia" on his left hand, resulting from dorsal root disease, easily distinguished a double response to pin prick. He reported that the first sensation, or "fast" pain was that of a sharp pin prick, and the second, or "slow" pain was of longer duration and not "pricking." $\mathrm{He}$ was of the opinion that the "slow" pain was different in quality from the "fast." On testing the other, or intact, upper extremity, the double response was also noted, but here the patient was uncertain whether the two pains were different in quality.

c. A patient with "hyperalgesia," paresthesias, and wasting of the extremities resulting from peripheral neuropathy associated with nutritional deficiency, was certain that the second sensation was of a different quality from the first, describing the first as brief "pricking" and the sec- 
ond as a prolonged "burning" sensation (Figure 4).

d. A patient with "hyperalgesia" of the right arm associated with a herpetiform eruption, when pricked on the affected side, described a sharp, brief "prick," followed by a prolonged "burning" sensation; on his intact arm, the two sensations were considered to be the same (Figure 4).

\section{Comment}

The reports of 19 normal subjects demonstrated again that the qualities of the two pain sensations of the double response on normal skin are not readily defined. The duration of each sensation was short and a contrast of their qualities difficult.

Boring (2) spent 15 months testing sensation on his arm and came to the conclusion that the qualities of the first and second responses differ. Lewis $(13,1)$, performing similar experiments with his co-workers, came to the conclusion that they were the same. The observations cited in $b, c$, and $d$, above, are more significant than those on normal subjects because the prolonged duration of the second or "burning" quality on patients with peripheral neuritis and dorsal root disease afforded a better opportunity for discrimination. These observations suggested again that the sensations associated with the first and second response are not identical.

In the following experiments, similar to those performed by Lewis and Pochin (12), an attempt has been made to ascertain which nerve fibers subserve "burning" and "pricking" pain sensations.

\section{Series 2}

$a$. In 3 subjects, ischemic block of the forearm lasting 35 to 75 minutes was produced. The "fast" pain was abolished long before the "slow" pain. A pin was used for stimulating. After 35 minutes of ischemia, no sensation was felt immediately upon impact of the pin. After about a second, however, a "burning" sensation was perceived. Pain of this "burning" quality was also produced by other means of noxious stimulation, including pinching, hair pulling, and burning. The delayed pain was always perceived as "burning." b. In 2 experiments on one subject, a solution of procaine hydrochloride was infiltrated about the ulnar nerve. In 9 experiments on 6 subjects, procaine was infiltrated subcutaneously beneath an area of skin $(5 \times 7 \mathrm{~cm}$.) on the dorsum of the hand. Observations were made during the period of incomplete analgesia: (1) immediately after infiltration and (2) as the effect of the procaine diminished.

During such incomplete analgesia, it was noted that "slow" pain was abolished while "fast" pain was retained. The quality of pin prick was not the same as that obtained on normal skin. It seemed to be sharper and less "full," as though a very fine needle were penetrating the skin. When thermal radiation was used as a noxious stimulus, the sensation was that of many tiny sharp needles being applied, similar to the familiar "pins and needles" sensation. There was no detectable sensation of "burning." The sensátion perceived was of a distinctly different quality from that felt on stimulation during ischemia.

c. In 12 experiments on 5 subjects, procaine hydrochloride was infiltrated in skin areas $(5 \times 7 \mathrm{~cm}$.) on the dorsum of the hand. The threshold for "pricking" pain was elevated in this area. Again, observations were made during the phase of incomplete analgesia immediately after injection, and as the action of the procaine diminished. In none of these experiments could a "burning" pain threshold be obtained during the period when the "pricking" pain threshold was elevated.

d. On 3 separate occasions in one subject, Dr. Bronson Ray infiltrated the tissue about the ulnar nerve with a solution of procaine hydrochloride, 1 per cent. The pain threshold of the skin area on the medial aspect of the wrist innervated by the ulnar nerve was ascertained immediately after the injection and during the phase of diminishing action of the procaine. In all 3 observations, the threshold for "pricking" pain was elevated,-in 1 instance, 189 per cent higher than the threshold on the control area. In this experiment, the first sensation perceived was a fine needle-like "pricking"; no "burning" pain was noted. The intensity of thermal radiation was great enough to produce a third degree burn. When the action of the procaine was ended, the subject experienced "burning" pain which persisted for 24 hours. 


\section{Comment}

The observations of Lewis and his co-workers, (1 and 12) and of Gasser and his co-workers (14 to 17) have given the double response special significance. Lewis found that the "fast" pain was more readily altered by ischemia than was "slow" pain. Gasser found that the function of myelinated fibers was more readily impaired during the ischemic state than was that of unmyelinated fibers, suggesting that "fast" pain is mediated by the former. Conversely, cocaine abolishes first the action of the slower-conducting, unmyelinated fibers. Lewis noted that when either the skin or the cutaneous nerve supplying it is cocainized, the "slow" pain response is abolished, while the "fast" pain response is retained. This suggested that the "slow" pain is subserved by unmyelinated fibers. The interval between the first and second responses, which increases with the distance of the stimulus from the cord, approximates the calculated time interval based on the conduction rate of impulses traveling in myelinated and unmyelinated fibers.

It was demonstrated by the observations of this communication that ischemic neuropathy interferes more with perception of "pricking" pain than with the perception of "burning" pain. Also, during the phases of incomplete analgesia following procaine infiltration, perception of "burning" pain was abolished, whereas "pricking" pain was still perceived.

Lewis ( 1 and 13) is of the opinion that regardless of whether "fast" or "slow" there is only "one quality" of skin pain, and that brief noxious stimulation of the skin produces a sensation described as "pricking" whereas prolonged noxious stimulation produces a sensation described as "burning." In contrast to this thesis, therefore, it can be inferred that the "pricking" quality of pain from the skin is "fast" pain, primarily conveyed by one set of fibers, i.e., myelinated fibers, whereas the "burning" quality is "slow" pain and is conveyed primarily by another set of fibers, i.e., unmyelinated fibers.

III. THE QUALITIES OF PAIN IN RELATION TO DEPTH OF STIMULATION IN THE SKIN

In an investigation of the double response (18), the depth of penetration of a needle into the skin was measured and related to the qualities of pain sensation perceived. It was found that the "fast" pain of the double response was obtained at a depth of 0.25 to $0.50 \mathrm{~mm}$., while the "slow" pain was obtained at a depth of 0.50 to $1.0 \mathrm{~mm}$.

\section{Observations}

Series 1. Scraping the most superficial portions of the skin of the dorsum of the hand with a fine needle gave rise to a sharp, pricking sensation. In 5 observations on 3 subjects, it was reported that when ischemia was induced in the arm for a sufficient length of time to abolish the "fast" pain or "pricking" component of the double response, scraping the superficial skin was painless. A deeper penetration of the skin with a needle gave rise to "burning" pain.

Series 2. In 7 instances in 3 subjects, perineural infiltration of the ulnar nerve with procaine hydrochloride, 1 per cent, and infiltration of a skin area $(5 \times 7 \mathrm{~cm}$.) on the dorsum of the hand, were performed. It was noted that during incomplete analgesia, immediately after injection and during the phase of diminishing action, scraping of the superficial skin with a needle gave rise to a tingling, pricking sensation, while deeper penetration of the needle was at the same time painless.

\section{Comment}

Two nerve fiber plexuses in the skin have been described (19) : an intraepidermal, or superficial, plexus supplied by myelinated fibers, and a subepithelial, or deeper, plexus supplied by unmyelinated fibers. Unfortunately, no conclusions can be drawn from these data concerning sensation.

Since ischemia eliminated painful responses from the most superficial portions of the skin before affecting the deeper, and since, at this time, the "fast" or "pricking" pain of the double response was also eliminated, it may be inferred that the apparatus for the "slow" pain alone was functioning, and that this lies deeper than the apparatus subserving "fast" pain.

This inference was supported by the observations made immediately following procaine infiltration of the skin, when the superficial "pricking" pain alone was perceived.

\section{INFERENCE CONCERNING THE "HYPERALGESIA" OF PERIPHERAL NEUROPATHY}

The sensory changes that occur during ischemia of an extremity resemble in many respects those 
which occur in the peripheral neuropathy of alcoholism with nutritional deficiencies (24), as well as in other varieties of peripheral neuropathies. Sensations subserved by the myelinated fibers are impaired before those subserved by the unmyelinated fibers.

It has been shown (Figure 3 ) that the ischemia was associated with first a lowering of the "pricking" and "burning" pain thresholds, and later with an elevation of both thresholds. Perhaps because it is transitory and of lesser magnitude, the phase of lowered "pricking" pain threshold in patients with peripheral neuropathy is seldom described. On the other hand, because of its persistence and greater magnitude, the lowering of the "burning" pain threshold is a striking bedside phenomenon. Perhaps relevant to these observations is the initial lowering of the threshold of stimulation of nerve fibers during ischemia and anoxia which has been noted by several investigators (20 to 22).

During the early stages of anoxia, the threshold of stimulation of the "C" group of fibers is markedly depressed, and possibly more so than is that of the "A" group. Moreover, the " $C$ " group of fibers maintains its phase of increased irritability longer than does the " $\mathrm{A}$ " group (23).

During ischemic neuropathy, "burning" pain long outlasted the period of stimulation; whereas on normal skin, "burning" pain ceased soon after the noxious stimulus ended. Such persistent pain was also reported by some patients with "hyperalgesic" skin areas due to peripheral nerve disorders. In these, there was no defect in circulation; hence, it is unlikely that the persistence of pain is due to a faulty blood flow.

It is seen in Figure 3 that, after about 15 minutes of ischemia, the "pricking" pain threshold had been elevated, while the threshold for "burning" pain was still decreasing. At this time, a pin point when pressed into the skin was less "pricking" and more "burning."

One author (24) suggested that such "paradoxic pain" resulted because the loss of one type of pain sensation enhanced the perception of another and supported this view by citing another (25), i.e., "that the function of the impulses which run on ahead of the others is to adjust the excitability of the synapses in preparation for the arrival of the later impulses." Thus, according to his views, if the impulses from myelinated fibers are lacking, there would be no synaptic adjustment and the undamped neural impulses would give rise to more intense sensation. Gasser (14 and 25), however, in the earlier formulation $(14,25)$ upon which the more recent worker based his views, concerned himself not with sensation, but with a simple spinal reflex pattern. $\mathrm{He}$ did not infer that a rapidly traveling impulse, as a result of noxious stimulation, alters a synaptic junction for another impulse from noxious stimulation so that the latter gives rise to a sensation of a different intensity or quality.

The data from the experiments of this communication suggest a simpler conception of the "paradoxic pain" of peripheral neuropathy: as the expression of a defect in peripheral nerve, the threshold for "burning" pain subserved by unmyelinated fibers is so depressed that ordinarily innocuous stimuli are perceived as painful, whereas at the same time the threshold for "pricking" pain, subserved by myelinated fibers, is elevated. Under these circumstances, contact with the bed clothes produces a painful burning, and yet pin prick perception is impaired.

\section{SUMMARY AND CONCLUSIONS}

1. The nature and significance of two pain sensations of the skin-"pricking" pain and "burning" pain-have been investigated.

2. The threshold for "burning" pain is lower than the threshold for "pricking" pain.

3. The peripheral nerve endings which subserve "pricking" pain are located more superficially in the skin than those subserving "burning" pain.

4. During the phase of incomplete analgesia following infiltration of procaine hydrochloride into the skin or about a peripheral nerve, "pricking" pain is perceived, whereas "burning" pain is abolished.

5. "Pricking" pain is the first or "fast" pain perceived in the double response to pin prick; "burning" pain is the second or "slow" pain.

6. Ischemic block of an extremity initially lowers the thresholds of "pricking" and "burning" pain. The threshold for "burning" pain is more depressed, and for a longer time, than the threshold for "pricking" pain. Also, during the period 
of depressed "burning" pain threshold, the sensation of "burning" pain long outlasts the noxious stimulus. Prolonged ischemic block produced an elevation of both "pricking" and "burning" pain thresholds, and ultimately complete analgesia.

7. The "hyperalgesia" associated with peripheral neuropathy in patients, may be explained by the significant depression of the "burning" pain threshold. This is usually accompanied by an elevated threshold for "pricking" pain.

8. These experiments together with the work of others, make it seem likely that "burning" pain is conveyed chiefly by unmyelinated fibers, and "pricking" pain chiefly by myelinated fibers.

\section{BIBLIOGRAPHY}

1. Lewis, T., Pain. Macmillan Co., New York, 1942.

2. Boring, E. G., Cutaneous sensation after nervedivision. Quart. J. Exper. Physiol., 1916, 10, 1.

3. Hardy, J. D., Wolff, H. G., and Goodell, H., Studies on pain: A new method for measuring pain threshold: Observations on spatial summation of pain. J. Clin. Invest., 1940, 19, 649.

4. Schumacher, G. A., Goodell, H., Hardy, J. D., and Wolff, H. G., Uniformity of the pain threshold in man. Science, 1940, 92, 110.

5. Hardy, J. D., Wolff, H. G., and Goodell, H., The pain threshold in man. A. Research Nerv. and Ment. Dis., Proc., 1943, $23,1$.

6. Wolff, H. G., Hardy, J. D., and Goodell, H., Studies on pain. Measurement of the effect of ethyl alcohol on the pain threshold and on the "alarm" reaction. J. Pharmacol. and Exper. Therap., 1942, 75, 38.

7. Wolff, H. G., Some Observations on Pain. Harvey Lectures, Science Press, Lancaster, Pa., 1944, p. 39.

8. Wolff, H. G., and Goodell, H., The relation of attitude and suggestion to the perception of and reaction to pain. A. Research Nerv. and Ment. Dis., Proc., 1943, 23, 434.

9. Wolff, H. G., Hardy, J. D., and Goodell, H., Studies on pain. Measurement of the effect of morphine, codeine, and other opiates on the pain threshold and an analysis of their relation to the pain experience. J. Clin. Invest., 1940, 19, 659.

10. Wolff, H. G., Hardy, J. D., and Goodell, H., Measurement of the effect on the pain threshold of acetylsalicylic acid, acetanilid, acetophenetidin, aminopyrine, ethyl alcohol, trichlorethylene, barbiturate, quinine, ergotamine tartrate, and caffeine: an analysis of their relation to the pain experience. J. Clin. Invest., 1941, 20, 63.

11. Schumacher, G. A., The influence of inflammation on the pain threshold of the skin in man. A. Research Nerv. and Ment. Dis., Proc., 1943, 23, 166.

12. Lewis, T., and Pochin, E. E., The double pain response of the human skin to a single stimulus. Clin. Sc., 1937-38, 3, 67.

13. Lewis, T., and Hess, W., Pain derived from the skin and the mechanism of its production. Clin. Sc., 1933-34, 1, 39.

14. Gasser, H. S., Conduction in nerves in relation to fiber types. A. Research Nerv. and Ment. Dis., Proc., 1934, 15, 35.

15. Gasser, H. S., Pain-producing impulses in peripheral nerves. A. Research Nerv. and Ment. Dis., Proc., 1943, 23, 44.

16. Clark, D., Hughes, J., and Gasser, H. S., Afferent function in the group of nerve fibers of slowest conduction velocity. Am. J. Physiol., 1935, 114, 69.

17. Gasser, H. S., and Erlanger, J., The role of fiber size in the establishment of a nerve block by pressure or cocaine. Am. J. Physiol., 1929, 88, 581.

18. Woollard, H. H., Weddell, G., and Harpman, J. A., Observations on the neurohistological basis of cutaneous pain. J. Anat., 1939, 74, 413.

19. Kuntz, A., and Hamilton, J. W., Afferent innervation of the skin. Anat. Record, 1938, 71, 387.

20. Heinbecker, P., Effect of anoxemia, carbon dioxide and lactic acid on electrical phenomena of myelinated fibers of the peripheral nervous system. Am. J. Physiol., 1929, 89, 58.

21. Thompson, M., and Kimball, H. S., Effect of local eschemia upon human nerve fibers in vivo. Proc. Soc. Exper. Biol. and Med., 1936, 34, 601.

21a. Bronk, D. W., The influence of circulation on the activity of nerve cells. A. Research Nerv. and Ment. Dis., Proc., 1937, 18, 298.

22. Lehmann, J. E., The effect of asphyxia on mammalian A nerve fibers. Am. J. Physiol., 1937, 119, 111.

23. Lorente de No, R., Personal communication.

24. Wortis, H., Stein, M. H., and Joliffe, N., Fiber dissociation in peripheral neuropathy. Arch. Int. Med., 1942, 69, 222.

25. Gasser, H. S., The Control of Excitation in the Nervous System. Harvey Lectures, Williams and Wilkins, Baltimore, 1937, p. 169. 